\title{
The role of the transport road network in the economic development of Saudi Arabia
}

\author{
M. Aldagheiri \\ Department of Geography, Qassim University, Saudi Arabia
}

\begin{abstract}
The development of the transport road network plays an important role in the economic development of a country and, therefore, the kilometre-age of paved roads existing in a country is often used as an index to assess the extent of its development. The proper development of the transport road network not only reduces the cost of transportation, both in terms of money and time, but also helps in the integration of various regions within the country and the better understanding of neighbouring countries at the international level. The transport road network in Saudi Arabia contributed to the development of the country by bringing in direct benefits from its role in the development of some sectors, such as minerals, agriculture, industry and commerce. In vast countries like the Kingdom of Saudi Arabia, where the main population centres are not only scattered all over the country but are also separated by deserts, sand dunes, valleys and mountains, a reliable transport road network becomes all the more important and essential. Therefore, this paper aims to identify the level of the transport road network in Saudi Arabia.
\end{abstract}

Keywords: transport road network, economic development, Saudi Arabia.

\section{Introduction}

Transport has become an important subject matter for geographers for two main reasons. Firstly, transport is a significant human activity with a strong spatial component. Secondly, it is an important factor influencing the spatial variation of many other social and economic activities (White and Senior [1]). Transport is the means by which people and commodities are moved from one place to another by a number of physical modes including roads, water, railways, airlines and pipelines. So transport in one form or another is a basic and essential part of 
the daily rhythm of life throughout the inhabited world (Hoyle [2]). Based on Mieczkowski [3] "the transport system may be likened to the blood circulation system in a living organism. Without it the organism dies". Transport is considered an essential feature of all modern economies. In general terms, as an economy grows and develops, it becomes more dependent upon its transport sector (Robinson and Bamford [4]).

Yeser [5] stated that transportation was considered for a long time to be the most important factor in regional, economic and social development. Transportation has an important role in increasing production, reducing travel times, increasing employment and improving accessibility. Furthermore, it plays an important role in reducing regional disparities and in improving the competitiveness of regions, by facilitating trade, the movement of labour, and economies of scale. The relationship between transportation infrastructure and economic development has been the focus of increasing analysis, discussion and interest during the past decade (Weiss [6], Felloni et al. [7], Weiss and Figura [8]). The importance of transportation infrastructure to economic growth has been recognized for a long time. There is no doubt that investment in transportation systems (e.g. roads, ports and railways) stimulated economic development in North America in the 19th century. Roads and railroads allowed the United States to expand from states hugging the coast of the Atlantic Ocean to all the land between the Atlantic and Pacific (Francois [9]). In addition, transportation infrastructure has expanded the range over which goods can be marketed. Although there is very little empirical evidence to this effect, it is generally believed that the U.S. government's massive investment in transportation infrastructure development in the 19th century led to the significant growth registered by the country's economy during that period (Gillen [10]).

According to Norton [11] the historical review of the evolution of the transport network relies on an examination of the interaction between the development of the transport system and economic development. In the broadest sense it includes factors such as population growth and human activities which have an impact on the landscape, influencing the evolution of transportation, and where the road network plays a significant role in facilitating all activities related to economic development. Robinson and Bamford stated that the road network is made up of single roads which link together two or more points, or centres, of movement. It may therefore be regarded as a set of inter-connected roadways along which movement takes place. Different modes of transportation form prominent landscape features and indeed roads, railway tracks, waterways and electricity structures form imposing features on the landscape and in wellpopulated, industrial and urban areas there is usually a dense pattern of transportation lines.

\section{Importance of the study}

The development of transport road network plays an important role in the economic development of a country and, therefore the kilometre-age of paved 
roads existing in a country is often used as an index to assess the extent of its development. The proper development of transport road network not only reduces the cost of transportation both in terms of money and time but also helps in the integration of various regions within the country and better understanding of neighbouring countries at the international level. The transport road network in Saudi Arabia contributed to the development of the country by bringing in direct benefits from its role in the development of some sectors such as minerals, agriculture, industry and commerce. In vast countries like the Kingdom of Saudi Arabia where the main population centres are not only scattered all over the country but are also separated by deserts, sand dunes, valleys and mountains, reliable transport road network become all the more important and essential. Therefore, this paper aims to identify the level of transport road network in Saudi Arabia.

\section{The relationship between the transport road network and economic development in Saudi Arabia}

Development of the road transport network plays an important role in the economic development of a country and, therefore the kilometres-age of paved roads existing in a country is often used as an index to assess the extent of its development. According to the Ministry of Transportation (MOT) [12] the proper development of a road network not only reduces the cost of transportation both in terms of money and time but also helps in the integration of various regions within the country and better understanding of the neighbouring countries on an international level. Roads contribute to the development of a country by bringing in direct benefits from their role in the development of activities such as agriculture, industry, commerce and mining and by bringing in indirect benefits from the enhancement in the value of property and the change it sets in the way of life and thinking of its people. It is therefore no wonder that all developed countries complete networks of roads and other transportation infrastructure and in the same way developing countries are making huge investments in developing and improving their transportation systems, including road networks.

In the vast Kingdom of Saudi Arabia, where the main population centres are not only scattered all over the country, but are also separated by deserts, sand dunes, valleys and mountains, fast and reliable means of transportation become all the more important and essential. The principal aim of road construction in Saudi Arabia is to connect major urban centres with surrounding villages and towns, thereby opening up the entire nation to development and enabling improvements in the quality of life by providing citizens with the ability to commute or move from place to place. Road construction has been a significant feature in the Kingdom's development, and has dictated patterns of traffic movement. Most development projects, whether for public services, religious purposes, agriculture or industry, have required the construction of new roads (MOT [13]). 
Various authors have researched and written about the road networks of Saudi Arabia. Saudi Arabia has been subjected to investigation and study in several Ph.D. theses and papers particularly focusing on transportation. For example, Abdo [14] examined the development of transport and road transport in Saudi Arabia. He also drew an historical picture of inland transport and described the pattern of caravan routes before and after the advent of Islam in the Arabian Peninsula. Mecci [15] studied and described in parts of his dissertation the effects of modern pilgrimage on transport in the city of Madinah.

Makki [16] investigated the problems of urban transportation in Makkah, giving a broad description of the pattern of roads and streets of the city of Makkah in his thesis. The impact of socio-economic change on Saudi urban transportation, particularly in the Eastern Region of Saudi Arabia, with special reference to the urban transportation of women, particularly by those in employment, has been examined and discussed by Amer Al-Metair [17]. Furthermore, Al-Rakeiba [18] examined the movement and transport of pilgrims in the Hajj Region in Saudi Arabia and applied some of the tools of road network analysis.

There are more recent studies in transport geography in Saudi Arabia. The first one is a thesis which aimed to study the road network as one of the main pillars of development in the Eastern Region of Saudi Arabia, examined and discussed by Najah Al-Qaraawi [19]. The second is a research project which examined the road transport network in Riyadh region, discussed by Alforih [20]. The third is an analysis of the efficiency of the road transport network in the Al-Qassim region, examined by Aldagheiri [21]. All used the analysis of the road network in their theses and applied several methods for this analysis, such as connectivity, accessibility, density etc.

It is helpful to subdivide the expansion of the modern road network from 1938 until the present day into two stages. The first stage is prior to the initial development plan from 1938 to 1970 (pre-1970) and the second following the initiation of the plan (post-1970). The two stages, pre-national planning and postnational planning, relate to the historical circumstances of the economic, political and social demands of the region. The activity during the second stage greatly exceeds that during the first owing to the existence of coordinated plans, high investment and concentration of effort.

\subsection{Pre-national planning}

This stage covers the period between the discovery of oil in 1936 and the first development plan in 1970, and starts with the formation of the first modern road in Saudi Arabia, which was built in 1938. The road, 73 kilometres in length, was built by Egypt with funding support received from the Wagfs of the Holy Mosques (Al Sayyad [22]). It connected the city of Jeddah with the holy places in Makkah and was primarily intended to serve the pilgrims arriving at the seaport of Jeddah. Relying on Al-Rakeiba there were some reasons for the Hajj region attracting modern roads before other parts of the Kingdom, as follows:

a) The region includes two holy cities of Makkah and Madinah, which are visited annually by large numbers of pilgrims. Development of 
transportation was an obvious requirement to facilitate the movement of pilgrims between Makkah, Madinah and the port of Jeddah, particularly since the Hijaz railway was destroyed in the First World War.

b) The economic position of the Saudi government at that time was poor. This situation permitted no development and, as has been stated above, the road which was built in the region was financed by non-Saudis, as all Muslim governments felt responsible for the holy cities and the development of the Hajj facilities.

c) On the other hand, the economic situation of the Hajj region in general, and its main cities in particular, was relatively better than the other areas of Saudi Arabia as a result of the Hajj revenue, which constituted about 50 per cent of the government's total revenue. This led to the Hajj region enjoying greater economic and social progress.

In the 1950s the Arabian-American Oil Company (Aramco) built the first asphalted road in the Eastern Region, where oil was discovered in 1936 and first produced in 1938. This road was 55 kilometres long, and linked Dammam and Ras-Tannurah. Although the Ministry of Communications was established in 1952, it was not until a year later that it assumed total responsibility for the nation's roads (Abd Arhman [23]). Based on the International Road Federation (IRF) [24], before the establishment of the Ministry, there were only 239 kilometres of paved roads in the Kingdom. The Ministry of Communications is responsible for the construction of the entire network of highways in the Kingdom, including all agricultural and feeder roads. Based on Abdo, the construction of the Madinah-Makkah road (424 kilometres in length), which was started in 1951 and completed in 1955, was the first instance of investment by the government of Saudi Arabia in roads. Consequently, in 1955 there were only two separate modern road networks: the first one in the Hijaz, Western Region, linking the holy places (a total of about 527 kilometres) and the second in the Eastern Region which connected the oil-fields with the main ports and cities (a total of about 400 kilometres).

In 1953, Riyadh was chosen as the government capital, and the need arose to link the capital with the economic areas in the east and the holy places in the west. The position of Riyadh, which is closer to the east than the west, and the attraction of economic prosperity, encouraged the government to link Riyadh with Dammam, first by railway which was completed by 1952, and then by road, which was completed in 1961. The new road also linked Riyadh with the main agricultural areas. The project to link Riyadh with the western part of the Kingdom started in 1961 and the road, 810 kilometres in length, linking the capital with the holy places, was completed in 1965 . This enabled travel from the Gulf area to the holy places along an east-west axis, Al-Rakeiba.

Subsequent expansion of the asphalted roads has diverged from the east-west axis, both northwards and southwards. The Makkah-Madinah road was extended to reach as far north as Tabuk (111 kilometres), and to the border with Jordan. The Tapline Road (300 kilometres), which followed the oil pipeline, starts in the east and extends northwest, parallel to the Kuwaiti, Iraqi and Jordanian borders and Saudi Arabia. However, in the pre-1970 period, the total length of paved 
road completed did not exceed 8,000 kilometres, 20 per cent of which was built by Aramco (MOT [25]).

\subsection{Post-national planning}

Over a period of three decades the Kingdom of Saudi Arabia has constructed a modern network of roads. This network has become a symbol of the modernization of the country and a national landmark, and is an integral part of government plans for both the public and private sectors of the Kingdom. The experience which has been gained in constructing this network and the upgrading of the nation's ability to undertake large highway construction projects under very difficult conditions, has given the Kingdom significant expertise in modern highway construction. In conjunction with the Kingdom's five-year plans, the Ministry of Transportation prepared its own comprehensive plan, which was known as the Five-Year Road Programme. The Post-Development Plans stages started in 1970 and have continued until the present time. In the year 1969 the Ministry of Transportation prepared a comprehensive five year plan for the development and maintenance of transportation infrastructure, including the road network. The advantage of preparing periodic plans is that expenditure over a period of years is estimated in advance, so that allocations can be indicated for each development activity. Thus it becomes possible to fix priorities in advance with the result that the development of the whole country can be carried out in a coordinated manner, with well defined objectives and targets.

The objectives of the Five-Year Road Programme were therefore designed to:

1. Promote the growth of other sectors while minimizing the overall cost of transportation required for their projected economic and social activity.

2. Promote national integration and regional economic growth. It was expected that on the completion of this plan all cities with populations of 10,000 or more would be connected with the main road either directly or by link roads.

3. Meet the expected growth in traffic at a minimum cost. This involved balancing the cost of maintaining the roads against the wear and tear on the vehicles using it plus the excessive time and cost of travel (MOT).

Based on the Ministry of Planning (MOP) [26] during the First Development Plan (1970 to 1975), 3,221 kilometres of new roads were constructed and 908 kilometres of existing roads were reconstructed. The most important road at this stage was the road on the coastal plain beside the Red Sea, which is about 1800 kilometres in length and extends from a northerly extreme on the SaudiJordanian border to a southerly extreme on the Saudi-Yemeni border. Although the main and secondary roads programme was sizeable in this development plan, public interest necessitated launching the Feeder Rural Roads Programme in order to connect villages and towns with the primary network. As Saudi Arabia is a vast country with numerous scattered small villages, it was initially decided to consider connecting the villages which were within 50 kilometres on either side of the main roads. Therefore, the programme of construction in this 
development plan completed 4,338 kilometres of rural and feeder roads. A maintenance programme for paved roads was also introduced during this period.

In the Second Development Plan (1975 to 1980), 11,399 kilometres of paved main roads and 10,053 kilometres of rural roads were constructed (MOP [27]). There were numerous geographical challenges to creating a comprehensive road system in Saudi Arabia such as the climate, the burning hot deserts and high mountain ranges which were each to pose different but equally challenging problems for contractors. In the south west of the Kingdom, where mountain ranges soar to 3,000 metres, a series of projects, involving the construction of magnificent viaducts, has been undertaken so that even the more inaccessible parts of the Kingdom in this region can be reached by road. Additionally, a 555 kilometre carriageway from Taif towards the southerly crossing of the mountain ranges of the Hejaz and Asser at Dahran Aljanob was built in this development plan.

During the Third Development Plan (1980 to 1985), the massive increase in traffic that ensued from the Kingdom's industrial and agricultural development necessitated the upgrading of many inter-city roads to expressways in various parts of the Kingdom, such as Jeddah-Makkah (70 kilometres), RiyadhDammam (388 kilometres), Riyadh-Sedir-Qassim (353 kilometres) and MakkahMadinah (424 kilometres) bringing the total road network to 25,000 kilometres of paved roads and 20,000 kilometres of agricultural roads (MOP, 1985). It is important to note here that the actual pace of road construction during this period surpassed the targets proposed in 1980 for all types of roads and the Ministry of Transportation spent $\$ 12.24$ billion on this construction, linking all cities and towns to the road network, (IRF). By the end of the third development plan, the Kingdom's physical transportation infrastructure was largely in place, so the focus of longer term development in the transport sector was on improving the operating efficiency of the system.

Mainly as a result of the huge infrastructure investment during the Third Development Plan, this was followed by a period of consolidation in the Fourth Development Plan (1985 to 1990), where the road construction programme focused on secondary and feeder roads, as well as on links to new and expanding agricultural areas. Secondary and feeder roads provide access to remote areas and connect village clusters. The total length of roads increased in this period to 81,500 kilometres, categorized as expressways and divided highways (3,500 kilometres), primary and feeder roads (26,500 kilometres), paved agricultural roads (3,000 kilometres) and agricultural roads (48,500 kilometres) (MOP, 1990). The most important road constructed in this stage was the motorway, which opened in 1985 between Dammam, Riyadh and Jeddah and was about 1,275 kilometres long. The Fourth Development Plan began in earnest with the planned shift in emphasis from road construction to maintenance. The growing need for ordinary and preventive maintenance resulted not only from the expansion of the main road network, but also from the damage caused to roads by overloading of trucks at a time when the demand for trucking services exceeded the supply capacity of the industry. In response to this problem, weight load limitations were enforced more strictly towards the end of the Third Plan 
The Length of Roads in Development Plans

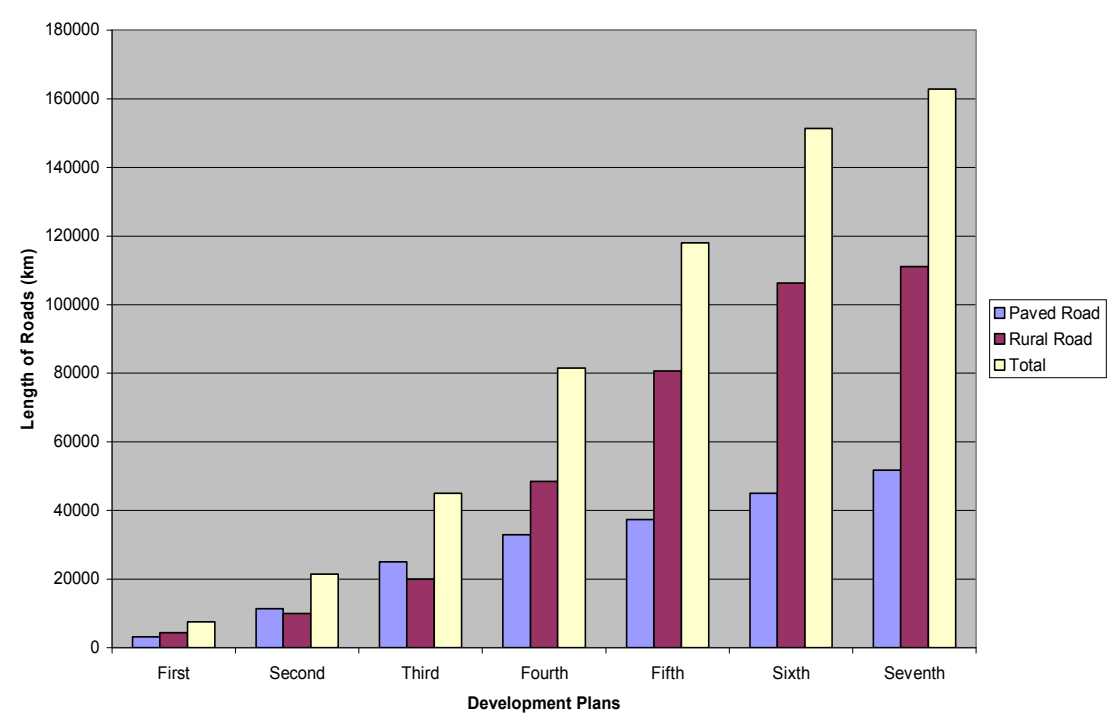

Figure 1: The length of roads in the development plans.

period, by operating weighing stations at strategic points of the road network. Hence, this plan was initiated on completion of the Third Development Plan's projects and focused on increased efficiency of operations and maintenance.

During the Fifth Development Plan (1990 to 1995), a total length of 4,322 kilometres of main paved roads was built and 32,169 kilometres of rural roads (MOP [28]). According to Abalkhai [29] the transport sector, and specifically the Ministry of Transportation, received $\$ 2,585$ billion from the government for the operation and maintenance of roadways and other projects at this stage. By 1991 the country boasted an excellent system of expressways and paved roads that linked all the populated areas of the kingdom. Highways constituted the backbone of the Saudi transportation system with about 100,000 kilometres of roads, 35,000 kilometres of which were paved. Some of the more important inter-city highways were; Dammam-Abu Hadriya- Ras-Tannurah Highway (257 kilometres), Khaybar-Al-Ola Highway (175 kilometres) and Taif-Abha-Jizan Highway (750 kilometres).

In the Sixth Development Plan (1995-2000), the road network played a crucial role in facilitating the flow of traffic. The length of the paved road network, built to high safety standards, reached 45,500 kilometres in 2000 compared to only 8,000 kilometres in 1970 . In addition, the total length of the rural road network serving the rural and agricultural areas had expanded to 106,300 kilometres in 2000 compared to only 3,500 kilometres in 1970 (MOP) [30]. As a result, the majority of the towns and cities and most of the villages of the Kingdom were linked by at least two-lane roads. In the context of improving 
efficiency and maintaining roads, the ordinary and preventive maintenance tasks carried out by the Ministry of Transportations covered about 37,000 kilometres of paved roads and bridges. The development of the roads network and improved efficiency led to a decline in traffic accidents from 167,300 in 1996 to 153,700 in 1998, or 8 per cent. The important issue in the Sixth Development Plan was encouraging the private sector to participate effectively in the provision of transport services, which constituted one of the significant directions of development strategy in the Kingdom (MOP [31]).

During the Seventh Development Plan (2000-2005), the total length of the paved road network increased to 51,800 kilometres and the rural road network increased to 111,000 kilometres (MOT [32]). The most important road is the 810 kilometres highway completed between Al-Qassim, Madinah, Yanbu, Rabigh and Thuwal. In addition a second highway started during this period between AlQassim and Hail, and has completed in the Eighth Development Plan period. There were major objectives in the Seventh Development Plan such as an improvement of the standard of operational efficiency and a reduction in dependence on government funding, together with an increase in private sector participation in the management and operation of transport facilities. Additionally, one of its objectives was to achieve a balance between the adequate expansion of domestic and international transport networks and the expected growth in demand and traffic on the one hand, whilst taking into account safety aspects and reducing adverse environmental impacts on the other.

\section{Conclusion}

Economic development and the transportation infrastructure are closely related. One reason for this positive relationship is that transportation infrastructure influences regional productivity through the facilitation of efficient movement of goods and labour used in production. Hence, improved transportation infrastructure can enhance the efficiency of goods and labour movement for production. The reduction in time and effort required to produce goods translates directly into increased regional productivity. Therefore the government of Saudi Arabia appreciates the importance of this sector and a lot has been achieved during the last few decades. Currently, Saudi Arabia is served by more than 165,000 kilometres of roads, about one-third of which are paved and the rest, improved earth. The considerable achievements described above are the result of various studies and programmes undertaken in co-ordination with a number of ministries and government agencies with regard to the perceived need for roads in the region. The overall objective was to connect all settlements in the Kingdom with the principal urban areas, thereby opening up channels for the government to provide necessary services for the entire population. Putting the Kingdom's road network in place has been one of the fundamental aims of the government in order to meet the basic requirements of national development. Without a functional and modern road network, national development on the scale achieved would not have been possible, as the existence of an adequate 
network of roads is a basic necessity for the economic and social progress of any developing country.

\section{References}

[1] White, H. and Senior, M., Transport geography, Longman, London, 1983.

[2] Hoyle, B. S., Transport and Development in Tropical Africa: Case Studies in the Developing World, London: John Murray, 1988.

[3] Mieczkowski, B., Transportation in Eastern Europe: empirical findings, East European Quarterly, Boulder, 1978.

[4] Robinson, H. and Bamford, C., Geography of transport, Macdonald \& Evans, Plymouth (Devon), 1978.

[5] Yeser, M., Transport and Development in the Yemen Arab Republic, Ph.D thesis, University of Wales, 1990.

[6] Weiss, J, Infrastructure and Economic Development, Economic Research Papers, African Development Bank, 50, pp. 1-37, 1999.

[7] Felloni, F, Wahl, T, and Wandschneider, P., Evidence of the Effect of Infrastructure on Agricultural Production and Productivity: Implications for China, Chinese Agriculture and the WTO, Proceedings of WCC-101, Seattle, Washington, 1999.

[8] Weiss, M. and Figura, P., A Provisional Typology of Highway Economic Development Projects, US DOT, Highway Administration: Washington DC, pp. 115-119, 2003.

[9] Francois, F., 21st Century Linkage Between Transportation and the Economy, Transportation Consultant: Transportation and Economic Development, Transportation Research Board (TRB) Committee on Transportation and Economic Development (A1A06), 2002.

[10] Gillen, D.W., Transportation infrastructure and economic development: A review of recent literature, Logistics and Transportation Review, 32, pp. 39-62, 1996.

[11] Norton, W., Historical analysis in geography, Longman, London, 1984.

[12] MOT, Ministry of Transportation, Roads and Ports in Saudi Arabia, Ministry of Transportation Press, Riyadh, 1971.

[13] MOT, Ministry of Transportation, The Roads in Saudi Arabia, Ministry of Transportation Press, Riyadh, 1985.

[14] Abdo, A., A geographical study of transport in Saudi Arabia, Ph.D thesis, University of Durham, England, 1969.

[15] Mecci, S. I., An analysis of the effects of modern pilgrimage on the urban geography of Medina, Ph.D thesis, University of Durham, UK, 1979.

[16] Makki, Z., Transportation problems in the city of Makkah outside the period of the Hajj, Ph.D thesis, University of Durham, UK, 1988.

[17] Al-Metair, A. N., Impact of socio-economic change on Saudi urban transportation, Eastern Region, Ph.D thesis, University of Durham, UK, 1987.

[18] Al-Rakeiba, A. S., Movement and transport of pilgrims in the Hajj Region, Saudi Arabia, Ph.D thesis, University of Durham, United Kingdom, 1991. 
[19] Al-Qaraawi, N., Transport roads network in the Eastern Province of the Kingdom of Saudi Arabia, Ph.D thesis, Al-Tubah (in Arabic), 1996.

[20] Alforih, A., The transport road network in Riyadh Region, Imam University, Riyadh (in Arabic), 2001.

[21] Aldagheiri, M, The Analysis of the Efficiency of Transport Road Network in the Al-Qassim Region, Saudi Arabia: A Geographical Study, MSc Dissertation, University of Leicester, UK, 2004.

[22] Al Sayyad, M., Transportation in Arab Countries, Cairo (In Arabic), 1956.

[23] Abd Arhman, A., The roads and transportation in The Kingdom (establishing and developing), Transport and Communications Magazine, No. 32, p. 28-30 (In Arabic), 2001.

[24] IRF, International Road Federation, The Saudi Arabia highway program: An IRF case history, Riyadh, 1986.

[25] MOT, Ministry of Transportation, Transport and Communication Progress and Achievements, Saudi Arabia, Riyadh, 1986.

[26] MOP, Ministry of Planning, The Second Development Plan, Ministry of Planning Press, Riyadh, 1975.

[27] MOP, Ministry of Plan, The Fourth Development Plan, Saudi Arabia, Ministry of Planning Press, Riyadh: Ministry of Planning Press, 1985.

[28] MOP, Ministry of Plan, Statistical Yearbook, Central Department of Statistics, Riyadh, 1997.

[29] Abalkhai, A., Socio-economic impacts of transportation and planning design for Saudi Arabia, Ph.D thesis, University of Strathclyde, UK, 1992.

[30] MOP, Ministry of Planning, The Seventh Development Plan, Ministry of Planning Press, Riyadh, 2000.

[31] MOP, Ministry of Plan, Statistical Yearbook, Central Department of Statistics, Riyadh, 2000.

[32] MOT, Ministry of Transportation, The ways of development, Saudi Arabia, Riyadh, 2003. 